\title{
ПАТОГЕНЕТИЧЕСКИЕ ФАКТОРЫ ДИСФУНКЦИИ АНТРАЛЬНОГО СФИНКТЕРА У ПАЦИЕНТОВ С ДИФФУЗНЫМ РЕФЛЮКС-ГАСТРИТОМ
}

Согласно классическим канонам физиологии частота и сила сокращений миоцитов стенки желудка определяется влиянием нервных импульсов от преганглионарных нейронов дорсального моторного ядра блуждающего нерва [5], эфферентных вегетативных нервных волокон, гормонов, гастроинтестинальных регуляторных пептидов и активности водителей ритма - клеток Кахаля [10]. В отношении координации сократительной деятельности различных участков мускулатуры желудка достоверно известны регуляторные влияния вегетативной нервной системы: холинергическая иннервация усиливает перистальтику желудка, но ослабляет тонус миоцитов антрального сфинктера, а стимуляция симпатических нервных волокон вызывает противоположные эффекты [1]. При этом перистальтика органа возможна ввиду различий нейромедиаторного состава эфферентных нервных волокон в продольном (холинергические) и циркулярном слоях (пептидергические, например, серотонинергические). Гладкие миоциты желудочно-кишечного тракта демонстрируют тонические (сфинктерные) и фазовые (несфинктерные) фенотипы [13]. Что касается функциональных различий моторной активности миоцитов стенки органа и сфинктеров, то ясности в этом вопросе до сих пор нет, поскольку сфинктеры желудочно-кишечного тракта имеют сложную двигательную хореографию, запрограммированную рефлексами и модулируемую гормонами [12]. До настоящего времени недостаточно физиологических, электрофизиологических и морфологических деталей сенсорной иннервации мышцы сфинктера для понимания физиологии пилорических афферентов и патогенеза рефлюксов. Открытие «желудочной проводящей системы» человека в виде интерстииальных клеток Кахаля (ИКК), тесно связанных с окончаниями кишечных двигательных нервов и электрически связанных с гладкомышечными клетками внутри мускулатуры желудка. [7], генерации медленных волн клетками Кахаля и установление связи дефектов ИКК с нарушением моторики и функциональными расстройствами желудка, оживили исследования желудочнокишечных аритмий [11], однако, не приблизили к пониманию физиологических механизмов разнонаправленной моторной активности миоцитов стенки органа и его сфинктеров.

Учитывая релаксирующий эффект простагландина Е2 на гладкомышечную ткань, выявленную связь дефектов или потери ИКК с патологической двигательной активностью желудка при гастропарезе у пациентов с сахарным диабетом [4], а также наличие у данных клеток рецепторов простагландина Е2 и реализацию их функций посредством экспрессии $\mathrm{Ca}^{2+}$ активированного Cl- канала Ano1 [6], вероятным видится модулирующее влияние данных эффекторов на моторную активность антрального сфинктера.

Цель работы - выявить патогенетические взаимосвязи между сенситивностью рецепторов серотонина и простагландина Е2 тромбоцитов, уровнем кальциемии и $\mathrm{pH}$ желудочного сока у пациентов с диффузным рефлюкс-гастритом.

\section{МАТЕРИАЛ И МЕТОДЫ}

Основную группу составили 79 пациентов отделений гастроэнтерологии и терапии ДОКТМО - 25 мужчин и 54 женщины (средней возраст 52,71+9,65 лет), у которых при ЭГДС был выявлены признаки дуоденогастрального рефлюкса, отсутствовали в анамнезе операции на ЖКТ и органах гепатобилиарной зоны. Всем больным проведена ЭГДС с помощью видеогастроскопа Pentax EG-2790K. Группу контроля составили 20 пациентов (13 женщин и 7 мужчин сходного возраста) без жалоб гастроэнтерологического профиля, которым была показана ЭГДС в связи с заболеваниями, не связанными с ЖКТ. Критериями исключения в основную и контрольную группу были: прием нестероидных противовос-

(c) Н.Н. Бондаренко, Д.С. Дубовик, 2020

(c) Университетская Клиника, 2020 
палительных, гормональных и цитостатических препаратов в течение последних 6 месяцев, прием антибактериальных, антисекреторных препаратов в течение последнего месяца, подозрение на наличие хирургической патологии.

Измерение степени агрегации тромбоцитов в тестах in vitro при инкубации плазмы, обогащенной тромбоцитами, с агонистами серотониновых и простагландиновых рецепторов проводили на биохимическом фотометрическом анализаторе АБхФк-02-«НПП-ТМ» БиАн [3]. Венозную кровь получали в 8 ч утра, натощак, после 14-часового голодания. Уровень ионизированного кальция $\left(\mathrm{iCa}^{2+}\right)$ в крови определяли с помощью колориметрического метода. У пациентов при ЭГДС производился забор желудочного содержимого для дальнейшего биохимического исследования. Внутрижелудочную $\mathrm{pH}$-метрию осуществляли микропроцессорным ацидогастрометром «АГМ-03» (АГМ-МП-03-1 фирмы НПП «Исток-Система»).

Статистическая обработка и анализ полученных данных проводился при помощи прикладной программы MedStat. Для проверки нормальности распределения количественных признаков использовали критерий КолмогороваСмирнова. Пороговое значение уровня статистической значимости принималось равным 0,05. В качестве описательной статистики для количественных переменных, имеющих нормальное распределение, использовались среднее значение $(\mathrm{M})$ и стандартное отклонение $(\sigma)$ в формате $\mathrm{M}^{ \pm} \sigma$. Для выявления связей между различными показателями использовался корреляционный анализ по Пирсону (с вычислением коэффициента корреляции $\mathrm{r}$ и оценкой его значимости $\mathrm{p})$.

\section{РЕЗУЛЬТАТЫ И ОБСУЖДЕНИЕ}

Инкубация с различными дозами (1, 5 и 10 мкM) серотонина адипината продемонстрировала дозозависимое увеличение агрегации тромбоцитов. У 94,93\% пациентов $(\mathrm{n}=75)$ не выявили достоверных отличий сенситивности ре- цепторов серотонина от таковой у пациентов контрольной группы - средняя эффективная концентрация серотонина адипината (ЕС50) составила 8,50 мкМ (против 8,86 мкМ в контроле).. что проявлялось наибольним приростом степени агрегации тромбоцитов преимущественно в диапазоне высоких концентраций лиганда (см. табл.). У 5,07\% пациентов дозозависимое повышение степени агрегации тромбоцитов отмечалось уже при низких концентрациях лиганда, а EC50 серотонина адипината была ниже таковой

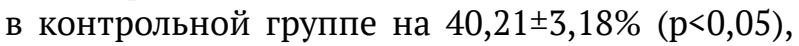
составив 5,30 мкМ. Данный факт свидетельствует о доминировании нормальной сенситивности серотониновых рецепторов у пациентов с диффузным поражением слизистой оболочки желудка.

При инкубации суспензии тромбоцитов с простагландином Е2 у 96,20\% пациентов (n=76) выявили повышение агрегации тромбоцитов, причем степень увеличения показателя нарастала дозозависимым способом. ЕС50 для простагландина Е2 составила 1,15 мкМ против 3,3 мкМ в контрольной группе, что отражает повышенную сенситивность простагландиновых рецепторов у большей части обследованных пациентов по сравнению с контрольной группой. Простагландины, синтезируемые с помощью циклооксигеназы-2, повышают чувствительность ноцицепторов, что снижает болевой порог, способствует развитию воспалительной реакции за счет стимуляции секреции интерлейкина1бета и фактора некроза опухолей-альфа.

Анализ полученных результатов позволяет говорить об отсутствии нарушений модулирующей функции серотонинергического отдела вегетативной нервной системы на моторную функцию стенки желудка, опосредованной 5-HT1А-, 5-НT3- и 5-НT4-рецепторами энтеральных нейронов и гладких миоцитов [9]. Кроме того, учитывая участие серотониновых рецепторов в регуляции регулярных и нерегулярных осцилляций в клетках Кахаля посредством 5-НТ2- (в том числе 5-НТ2В-рецепторов), 5-НT3-

Степень агрегации тромбоцитов (\%) у пациентов с очаговым рефлюкс-гастритом

Таблица. при инкубации in vitro с различными лигандами, $\mathrm{M} \pm \mathrm{m}$

\begin{tabular}{lcccccc}
\hline & \multicolumn{5}{c}{ Лиганды } \\
\cline { 2 - 7 } Группы пациентов & \multicolumn{3}{c}{ Серотонина адипинат } & \multicolumn{3}{c}{ Простагландин Е2 } \\
\cline { 2 - 7 } & 1 мкM & 5 мкM & 10 мкM & 1 мкM & 5 мкM & 10 мкM \\
\hline \hline Контрольная $(\mathrm{n}=20)$ & $11,79 \pm 0,52$ & $36,72 \pm 1,74$ & $52,09 \pm 2,77$ & $40,71 \pm 1,96$ & $69,54 \pm 4,28$ & $75,66 \pm 3,99$ \\
\hline Основная $(\mathrm{n}=79)$ & $10,95 \pm 1,33$ & $39,11 \pm 2,73$ & $50,72 \pm 2,64$ & $49,22 \pm 2,58^{*}$ & $83,86 \pm 3,29 *$ & $91,03 \pm 3,87 *$ \\
\hline
\end{tabular}

Примечание: * - различия достоверны р<0,05. 
и 5-НT4-рецепторов [2], можно считать адекватной пейсмеккерную функцию ИКК.

Возможным механизмом разнонаправленных физиологических свойств гладких миоцитов сфинктеров (тонических) и стенки желудка (фазных) может быть вовлечение различных внутриклеточных эффекторных систем-цАМФ-, цГМФ-зависимых, а также $\mathrm{Ca}^{2+}$-зависимых протеинкиназ [5]. В этой связи выявленная нами повышенная сенситивность рецепторов ПГЕ2 может сопровождаться изменением проницаемости плазмолеммы клеток для ионов $\mathrm{Ca}^{2+}$ и $\mathrm{Na}+$, активацией ацетилхолиновых рецепторов в нервно-мышечном соединении, увеличением или уменьшением внутриклеточного уровня цАМФ в гладких миоцитах и/или ИКК [8], что определяется содержанием $\mathrm{Ca}^{2+}$ в крови.

Анализ содержания $\mathrm{iCa}^{2+}$ в крови $98,33 \%$ обследованных пациентов показал снижение аналогичного показателя по сравнению с контрольной группой на $20,78 \pm 2,50 \%(p<0,05)$. В этой связи следовало ожидать нарушение физиологических эффектов парасимпатического отдела вегетативной нервной системы на сокращение гладкомышечных клеток, поскольку начальная фаза двухфазного ответа M3-мускаринового рецептора является $\mathrm{Ca}^{2+}$-зависимым процессом, происходит через начальную полимеризацию актина, и регулируется $\mathrm{Ca}^{2+} /$ кальмодулинзависимым ферментом MLCK, что в итоге приводит к фосфорилированию легкой цепи миозина 20 (MLC 20) [5], вызывая первоначальное мышечное сокращение.

В антральном отделе желудка рН желудочного сока у обследованных пациентов была выше контрольной на $56,27 \pm 3,01 \%(\mathrm{p}<0,05)$. Смещение pH в щелочную сторону может быть обусловлено как присутствием у пациентов эндоскопических признаков дуоденогастрального рефлюкса, так и ингибирующим влиянием ПГЕ2 на секрецию желудочного сока и повышает выработку слизи, что является цитопротективным эффектом.
Анализ корреляционных связей между изученными показателями. В результате выявили прямую корреляционную связь между повышенной $\mathrm{pH}$ желудочного содержимого и чувствительностью рецепторов тромбоцитов к низким дозам ПГЕ2 (1 мкМ) (r=0,598 против $\mathrm{r}=0,371$ в контроле) при отрицательной связи между кислотностью и уровнем $\mathrm{iCa}^{2+}$ в крови $(\mathrm{r}=-0,726$ против $\mathrm{r}=0,456$ в контроле). Отсутствие взаимосвязи между сенситивностью серотониновых рецепторов и $\mathrm{pH}$ желудка может свидетельствовать о нарушении модулирующей роли данного отдела нервной системы в прямой и опосредованной G-клетками регуляции секреции компонентов соляной кислоты $[1,12]$. Обратная взаимосвязь уровня $\mathrm{iCa}^{2+} \mathrm{c} \mathrm{pH}$ желудочного сока может отражать нарушение реализации парасимпатических влияний в контроле секреции компонентов соляной кислоты.

Повышение значений $\mathrm{pH}$ в антральном отделе желудка обследованных пациентов при повышенной сенситивность простагландиновых рецепторов может отражать отсутствие активирующего эффекта ПГЕ2 на ИКК, а также нарушение функционирования «антродуоденального тормозного механизма», регулирующего высвобождение гастрина и возобновление секреции компонентов соляной кислоты в желудке.

\section{З А К Л Ю Ч Н ИЕ}

Таким образом, выявленные у пациентов с рефлюкс-гастритом при диффузном поражении слизистой оболочки у пациентов повышенная сенситивность рецепторов ПГЕ2, снижение уровня ионизированного кальция в крови и нарушение функционирования «антродуоденального тормозного механизма» могут быть патогенетическими факторами нарушения взаимодействия интерстициальных клеток Кахаля и гладких миоцитов пилорического сфинктера.

\section{Н.Н. Бондаренко, Д.С. Дубовик}

ГОО ВПО «Донецкий национальный медицинский университет имени М. Горького», Донецк

\section{ПАТОГЕНЕТИЧЕСКИЕ ФАКТОРЫ ДИСФУНКЦИИ АНТРАЛЬНОГО СФИНКТЕРА У ПАЦИЕНТОВ С ДИФФУЗНЫМ РЕФЛЮКС-ГАСТРИТОМ}

Исследовали зависимость сенситивности рецепторов серотонина и простагландина Е2 тромбоцитов, уровня кальциемии и $\mathrm{pH}$ желудочного сока у пациентов с диффузным рефлюкс-гастритом и признаками дуоденогастрального рефлюкса. Выявили прямую корреляционную связь между повышенной $\mathrm{pH}$ желу- дочного содержимого и чувствительностью рецепторов тромбоцитов к низким дозам простагландина E2 (1 мкM) (r=0,598), при отрицательной связи между кислотностью и уровнем ионизированного кальция в крови $(\mathrm{r}=-0,726)$. Выявленные повышенная сенситивность рецепторов ПГЕ2, снижение уровня ионизиро- 
ванного кальция в крови и нарушение функционирования «антродуоденального тормозного механизма» могут быть патогенетическими факторами нарушения взаимодействия интерстициальных клеток Каха- ля и гладких миоцитов пилорического сфинктера.

Ключевые слова: сенситивность рецепторов тромбоцитов, кальциемия, дуоденогастральный рефлюкс, рефлюкс-гастрит.

\section{N.N. Bondarenko, D.S. Dubovik}

SEI HPE «M. Gorky Donetsk National Medical University», Donetsk

\section{PATHOGENETIC FACTORS OF ANTHRAL SPHINTER DYSFUNCTION IN DIFFUSE REFLUX GASTRITIS PATIENTS}

The correlation between platelet serotonin and prostaglandin E2 receptors sensitivity, blood calcium concentration and gastric $\mathrm{pH}$ in patients with diffuse reflux gastritis was analysed. Direct correlation between the increased gastric $\mathrm{pH}$ and platelet receptors sensitivity to low doses of prostaglandin E2 $(1 \mathrm{mcM})(\mathrm{r}=0,598)$ with reverse correlation between the acidity and ionised calcium blood level $(r=-0,726)$. The revealed increased sen- sitivity of prostaglandin E2 receptors, a decrease in the level of ionized calcium in the blood and a disruption in the functioning of the "antroduodenal inhibitory mechanism" can be pathogenetic factors in the disruption of the interaction of Cajal interstitial cells and smooth myocytes of the pyloric sphincter

Key words: platelet receptors sensitivity, blood calcium level, duodeno-gastral reflux, reflux gastritis.

\section{ЛИТЕРАТУРА}

1. Варванина Г.Г., Ткаченко Е.В., Дроздов В.Н. Роль простагландинов E2 и F2 $\alpha$ в развитии эрозивно-язвенных поражений гастродуоденальной зоны. Экспериментальная и клиническая гастроентерология. 2009; 4: 1316.

2. Лычкова А.Э. Серотониновая регуляция моторной функции тонкой кишки. Экспериментальная и клиническая гастроэнтерология. 2011; 3: 130-135.

3. Филиппова О.И., Колосков А.В., Столица А.А. Методы исследования функциональной активности тромбоцитов (обзор литературы). Трансфузиология. 2012; 13 (2): 493-514.

4. Blair P. J., Hwang S. J., Shonnard M. C.,et al. The Role of Prostaglandins in Disrupted Gastric Motor Activity Associated With Type 2 Diabetes. Diabetes 2019; 68 (3): 637647.

5. Cruz M. T., Dezfuli G., Murphy E.C., et al. GABAB Receptor Signaling in the Dorsal Motor Nucleus of the Vagus Stimulates Gastric Motility via a Cholinergic Pathway. Front Neurosci. 2019; 13: 967.

6. Drumm B.T., Hwang S.J., Baker S.A. et al. $\mathrm{Ca}^{2+}$ signaling behaviours of intramuscular interstitial cells of Cajal in the murine colon. J. Physiol. 2019; 597 (14): 3587-3617.

7. Drumm B.T., Sung T.S., Zheng H. et al. The effects of mitochondrial inhibitors on $\mathrm{Ca}^{2+}$ signalling and electrical conductances required for pacemaking in interstitial cells of Cajal in the mouse small intestine. Cell Calcium. 2018; 72: 1-17.

8. Mahavadi S., Nalli A.D., Wang H. et al. Regulation of gastric smooth muscle contraction via $\mathrm{Ca}^{2+}$-dependent and $\mathrm{Ca}^{2+}$-independent actin polymerization. PLoS One. 2018; 13 (12): e0209359.

9. Mawe G.M., Hoffman J.M. Serotonin Signaling in the Gastrointestinal Tract: Functions, dysfunctions, and therapeutic targets. Nat. Rev. Gastroenterol. Hepatol. 2013; 10 (8): $473-486$.

10. Sanders K.M., Kito Y., Hwang S.J., Ward S.M. Regulation of Gastrointestinal Smooth Muscle Function by Interstitial Cells. Physiology (Bethesda). 2016; 31 (5): 316-326.

11. Sanders K. M. Spontaneous Electrical Activity and Rhythmicity in Gastrointestinal Smooth Muscles. Adv Exp Med Biol. 2019; 1124: 3-46.

12. Powley T. L., Hudson Ch. N., McAdams J. L. et al. Organization of Vagal Afferents in Pylorus: Mechanoreceptors

\section{REFERENCES}

1. Varvanina G.G., Tkachenko E.V., Drozdov V.N. Rol' prostaglandinov E2 i F2 $\alpha$ v razvitii erozivno-yazvennyh porazhenij gastroduodenal'noj zony. Eksperimental'naya i klinicheskaya gastroenterologiya. 2009; 4: 13-16 (in Russian).

2. Lychkova A.E. Serotoninovaya regulyaciya motornoj funkcii tonkoj kishki. Eksperimental'naya i klinicheskaya gastroenterologiya. 2011; 3: 130-135 (in Russian).

3. Filippova O.I., Koloskov A.V., Stolica A.A. Metody issledovaniya funkcional'noj aktivnosti trombocitov (obzor literatury). Transfuziologiya. 2012; 13 (2): 493-514 (in Russian).

4. Blair P. J., Hwang S. J., Shonnard M. C.,et al. The Role of Prostaglandins in Disrupted Gastric Motor Activity Associated With Type 2 Diabetes. Diabetes 2019; 68 (3): 637647.

5. Cruz M. T., Dezfuli G., Murphy E.C., et al. GABAB Receptor Signaling in the Dorsal Motor Nucleus of the Vagus Stimulates Gastric Motility via a Cholinergic Pathway. Front Neurosci. 2019; 13: 967.

6. Drumm B.T., Hwang S.J., Baker S.A. et al. $\mathrm{Ca}^{2+}$ signaling behaviours of intramuscular interstitial cells of Cajal in the murine colon. J. Physiol. 2019; 597 (14): 3587-3617.

7. Drumm B.T., Sung T.S., Zheng H. et al. The effects of mitochondrial inhibitors on $\mathrm{Ca}^{2+}$ signalling and electrical conductances required for pacemaking in interstitial cells of Cajal in the mouse small intestine. Cell Calcium. 2018; 72: 1-17.

8. Mahavadi S., Nalli A.D., Wang H. et al. Regulation of gastric smooth muscle contraction via $\mathrm{Ca}^{2+}$-dependent and $\mathrm{Ca}^{2+}$-independent actin polymerization. PLoS One. 2018; 13 (12): e0209359.

9. Mawe G.M., Hoffman J.M. Serotonin Signaling in the Gastrointestinal Tract: Functions, dysfunctions, and therapeutic targets. Nat. Rev. Gastroenterol. Hepatol. 2013; 10 (8): 473-486.

10. Sanders K.M., Kito Y., Hwang S.J., Ward S.M. Regulation of Gastrointestinal Smooth Muscle Function by Interstitial Cells. Physiology (Bethesda). 2016; 31 (5): 316-326.

11. Sanders K. M. Spontaneous Electrical Activity and Rhythmicity in Gastrointestinal Smooth Muscles. Adv Exp Med Biol. 2019; 1124: 3-46.

12. Powley T. L., Hudson Ch. N., McAdams J. L., et al. Organization of Vagal Afferents in Pylorus: Mechanoreceptors Arrayed for High Sensitivity and Fine Spatial Resolution?. 
Arrayed for High Sensitivity and Fine Spatial Resolution?. Auton Neurosci. 2014; 10: 36-48.

13. Rego S.L., Zakhem E., Orlando G., Bitar K. N.. Bioengineering functional human sphincteric and non-sphincteric gastrointestinal smooth muscle constructs. Methods. 2016; 99: 128-134.
Auton Neurosci. 2014; 10: 36-48.

13. Rego S.L., Zakhem E., Orlando G., Bitar K. N.. Bioengineering functional human sphincteric and non-sphincteric gastrointestinal smooth muscle constructs. Methods. 2016; 99: 128-134. 